\title{
The Reputation Effect: A Case Study of Credit Contracts in Transition Economies
}

\author{
Lionel Artige ${ }^{a}$ and Rosella Nicolini $i^{b 1}$ \\ ${ }^{a}$ HEC, Department of Economics, Université de Liège, Belgium \\ ${ }^{\mathrm{b}}$ Department of Applied Economics, Univesitat Autònoma de Barcelona, Spain
}

\begin{abstract}
This paper proposes an empirical analysis of the role of memory in determining the size of credits granted by the European Bank for Reconstruction and Development (EBRD) during 1991-2003. We first build an original database from information associated with the number and contract types granted by clients, after which we develop an empirical strategy for capturing the role of memory, namely by defining three different indicators to approximate each client's reputation. These indicators rely on the client's identity and, when available, information associated with previous EBRD-financed investment projects. With the fixedeffects estimation technique, our results unambiguously show that the value of the first investment project financed by the EBRD, as a proxy for reputation, is the most effective indicator for established clients to determine the size of the credits they receive to finance further investments.
\end{abstract}

Keywords: International Lending; Screening Devices; Fixed-Effects Technique

JEL: $F 34, G 21, P 33$

(C) 2015 Published by SSBFNET

\footnotetext{
${ }^{1}$ Corresponding author: Universitat Autònoma de Barcelona, Edifici B - Campus UAB, 08913 Bellaterra, Barcelona, Spain. telephone: +34935814573 ; fax +34935812292
} 


\section{Introduction}

The European Bank for Reconstruction and Development (EBRD) was established in 1990 to assist the political and economic transformation of post-socialist countries in central and eastern Europe. In the chapters of the EBRD Creation Agreement, promoters of the new institution identified that the bank's chief mode of action would be financing individual projects intended primarily to develop private-sector enterprises. This mission, however, came with a concern: financing investments that would not otherwise be funded, yet that posed catalytic power in host economies. If there were a non-EBRD solution for receiving credits, then potential clients would certainly avoid involvement with the EBRD, whose loan rates were not subsidized and whose projects were required to impact the economic transition process (Besley et al., 2010). In this respect, the EBRD's mission was not to crowd out private bank financing, but to operate in countries and finance projects that no commercial bank would consider. Therefore, de jure et de facto, as soon as the EBRD was established, it had a dominant position in financing investment projects proposed for transition economies. 2

However, like any other credit institution, the EBRD faced the problem of needing to screen clients and to choose projects with the highest expected returns. This exceptional situation makes the EBRD's experience an interesting case to study for two reasons. First, the management of risk had to be conducted in a highly uncertain environment. Owing to macroeconomic turmoil, the country risk was great, and all potential borrowers lacked market experience and any history of creditworthiness. Second, decisions made by the EBRD remained unaffected by competition, for local banks were insolvent and foreign banks did not enter these risky markets during the early transition period (Lanine and Vander Vennet, 2007).

Given the original features of the evidence applied in our study, we do not propose a study to compare the EBRD's behavior in the credit market with that of other commercial banks. Instead, we propose an empirical exercise to identify the signal(s) that the EBRD may have exploited to embed the idea of reputation and, in turn, to establish a screening mechanism for fixing the amount of credits granted to selected applicants. For this, we recognize that banks tend to maintain durable relationships with clients of established reputation. With repeated contracts, the principal (i.e., the bank) is able to learn from the agent's past performance and thus propose a contract that internalizes this information over time. Ultimately, the benefit is improved risk sharing (Stiglitz and Weiss 1981, 1983). In our investigation of reputation, we aim to understand how the EBRD could have exploited the effect of reputation in defining the size of credits granted to clients who received multiple credits. In this respect, we propose an empirical approach to emphasize the role of the learning process — namely, memory as a proxy for reputation-as a screening device.

The EBRD's monopolistic behavior in the 1990s offers ideal conditions for testing the issue. We build an original database with data from credit contracts granted for investments to private and public firms during the first 13 years of EBRD's activity (1991-2003) based on its own releases. Our dataset allows us to split contracts into two subpopulations - one of firms that signed a single contract, the other of firms that signed multiple contracts — which enables us to develop an identification strategy to control for the screening effect. In both subpopulations, the loan amount and contract type set for each firm's first contract form the outcome of the EBRD's screening policy. For the subpopulation of multi-contract firms, information about the firms' previous actions was available, though it remains unclear whether the EBRD used it. We address this question by implementing an ad hoc empirical strategy that exploits the properties of the fixed-effects estimator. We identify an estimation model that allows us to detect a group of potential determinants of the size of the credit granted, after which we run regressions by applying the previous specification to both subpopulations. We rely on the fixed-effects estimation method, in which we

\footnotetext{
${ }^{2}$ Despite the EBRD's dealings with government-owned commercial banks (e.g., Dinç, 2005), the bank's institutional origins as well as the composition of its board of directors - namely, the representatives of 61 countries and two intergovernmental institutions - made it nearly impossible for politicians to make decisions about credit lending to further their political goals.
} 
introduce in turn three different types of fixed effects, each representing a different way of considering the client's reputation effect.

If the same results were obtained in the three cases, then it would mean that the EBRD did not draw on its history with these clients in designing contracts. However, our results clearly show that such was not the case. The total project value of the first signed contract is neatly identified as the dominant borrower fixed effect that plays a significant role in explaining the size of additional contracts that the EBRD granted to the client.

In what follows of this paper, Section 2 focuses on the primary theoretical contributions derived from studying the bank-client relationship, after which Section 3 presents evidence from our case study. Section 4 describes the econometric strategy and results, followed by our conclusions in Section 5.

\section{The Choice of Contracts: A Brief Literature Review}

Determining the optimal contract for both a lender and borrower has been widely studied. The major source of risk between the two counterparties is asymmetric information that is quite difficult to control for. Lenders aim to define a strategy that allows them (i) to distinguish good (i.e., solvent) borrowers from bad ones and (ii) to choose appropriate incentives that force borrowers to put their utmost effort toward completing the investment project for which credit is sought. The problem is thus the sum of various dimensions of uncertainty and imperfect information.

A bank can usually discriminate clients by offering them different contracts. Though these contracts can be grouped by type, each contract is usually tailored to the individual client's needs. Examining the most widespread class of contracts, Inderst and Mueller (2006) investigate the optimality of equity versus debt contracts, the latter of which are found to be optimal when the lender is conservative, while the former are optimal when he or she is aggressive. Debt contracts are suitable for financing profitable projects that are likely to break even solely in light of public information, while less profitable projects are financed with equity. In effect, debt contracts can mitigate moral hazard and other problems arising from asymmetric information. For instance, investments by small firms in tangible assets such as equipment or property are expected to be financed with debt contracts Inderst and Mueller (2006) also analyze the suboptimality of a lender's decision to propose a contract to a potential borrower by choosing from a menu of contracts after having observed ex ante a public signal. Choosing from such a menu always creates a problem because lenders always choose contracts that are ex post optimal for them. Nevertheless, given that lenders optimally restrict themselves to a single contract in order to avoid ex post self-dealing, it is optimal to offer a single contract that the client can accept or reject based on its conditions. Not offering any provision for adjusting the loan terms after screening guarantees the optimality of the decision, which the authors provide empirical evidence to support. Loans are often granted at standardized terms, and borrowers in particular small firms are often charged the same rate of interest given the implicit same-risk premium. However, their arguments emerge from evidence from a competitive market, which invites speculation about the differences in a bank's attitudes toward the screening process in monopolistic markets.

While the screening process is a key tool for discriminating clients, it poses a real burden for banks (Manove et al., 2001). In short, the process is costly. Manove et al. (2001) focus on the screening cost for a monopolistic bank in the credit market to show the vast difference regarding the standard competitive structure. For monopolistic banks, the optimal strategy involves offering a unique contract and subsequently screening all projects. The motivation is straightforward: the structure of the credit market makes the demand quite inelastic, and high interest rates do not lower the borrowing volume. Here, the important factor is the market power of the bank, which remains efficient under conditions of asymmetric information. Since information is generated at a cost to the bank throughout the screening process, the bank screens clients, funds better projects, and covers its costs with higher interest rates. As for borrowers, the good ones are thereby incentivized to distinguish themselves.

As described in Section 3, the framework developed by Manove et al. (2001) perfectly fits the behavior adopted by the EBRD. In this theoretical framework, the reputation effect is crucial to building a memory of clients and, in the 
long run, turns out to be a discriminating device. In this sense, the EBRD provides a remarkable case study for naturally investigating the previous issue.

\section{The EBRD-Client Relationship}

When considering potential clients for loan contracts, the EBRD followed a highly standard procedure (Vuylsteke, 1995). For our study, we first consider the case of financing an investment project only. For this, the bank and its client agree to sign a contract, and the bank finances the firm, which upon making the investment pays back the loan plus interest to the bank.3 Second, we consider the subsequently more established bank-client relationship; after the bank grants its first contract to a firm, depending on the client's behavior it can decide whether to finance a second project should the client apply for an additional contract.

In these circumstances, the bank can draft a contract by adapting the terms of the contract for the second period while taking into account the return of the firm's investment from the first period (Chiappori et al., 1994). In short, the bank recalls the return on the firm's first-period investment. The structure of such a contract is thus optimal; neither the principal (i.e., the bank) nor the agent (i.e., the firm) has any incentive to deviate. In this sense, our empirical exercise aims to identify whether and to what extent reputation impacts the amount of credit granted by the EBRD to finance repeat clients' investment projects.

For the purposes of this study, we build an original database from data made public by the EBRD over time. Our database includes all 1,780 financial contracts signed by the EBRD with private and public clients during 19912003 and contains information for each case about the client's identity and nationality, the amount of the contract in euros (EUR), the value of the investment project, the sector of investment, the year when the contract was signed, the type of contract (i.e., loan, share, equity, or guarantee), and other characteristics (e.g., previous clienthood, private- or public-sector operation, and macroprograms). Artige and Nicolini (2013) provide an extensive description of the database contents, for which three main categories of credit instruments can be distinguished: loans, guarantees, and share and equity contracts. Loans were the financial contract most frequently employed by the EBRD during 1991-2003 (Table 1). A loan is generally considered to be a short-term contract lasting five years on average and tailored to meet the particular requirements of the project. The credit risk is usually assumed by the bank or partially syndicated to the market.

Table 1: EBRD contracts and their frequency (1991-2003)

\begin{tabular}{|c|c|c|}
\hline Contract & Freq. & $\%$ \\
\hline Debt & 1 & 0.06 \\
\hline Equity & 141 & 7.92 \\
\hline Guarantee & 100 & 5.62 \\
\hline Line of Credit & 7 & 0.39 \\
\hline Loan & 949 & 53.31 \\
\hline Loan/Line of credit & 1 & 0.06 \\
\hline Loan/Shares & 96 & 5.39 \\
\hline Loan/Guarantee & 1 & 0.06 \\
\hline Senior debt & 72 & 4.04 \\
\hline Shares & 404 & 22.70 \\
\hline
\end{tabular}

\footnotetext{
${ }^{3}$ In this section, for the sake of simplicity, we use "loan" to mean any kind of credit contract the bank proposes.
} 


\begin{tabular}{|l|c|l|}
\hline Shares/Loan & 2 & 0.11 \\
Shares/Loan/Share & 1 & 0.06 \\
Table continued & 1 & 0.06 \\
Share/Loan/Guarantee & 4 & 0.22 \\
Subordinated debt & $\mathbf{1 7 8 0}$ & $\mathbf{1 0 0}$ \\
TOTAL & & \\
\hline
\end{tabular}

Source: EBRD, Calculus: authors

The second category includes share and equity contracts. In the EBRD's case, most share contracts were signed at the beginning of the EBRD's activity, while equity contracts represent a broader category of financial contracts that includes share contracts. An equity investment can be undertaken in various forms, including as a subscription to ordinary shares. When the EBRD takes an equity stake, it expects an appropriate return on its investment. The bank usually sells its equity investment on a non-recourse basis so that it can have a clear exit strategy and take only a minority position. 4

Lastly, the third category of credit instruments refers to guarantee contracts, which were mostly used at the end of our dataset period. With this type of contract, the EBRD helped borrowers to gain access to financial sources via the provision of guarantees (EBRD, 1999).

The difference in the distribution of probability of having a single contract or multiple contracts granted may signal that the EBRD did not behave similarly with first contracts as it did with any subsequent ones. Since any bank has less client information for a first contract than for a second, the first poses greater risk for the bank, which in response is likely to adjust its lending policy. If so, then we may formulate a hypothesis that the EBRD's lending policy does not consist of offering a menu of standard contracts but instead of granting credits tailored according to client information and possibly whether the contract is the first or a subsequent one.

\section{Empirical Strategy}

When deciding to finance a firm's investment project, the EBRD selects one of 13 available contracts (Table 1). The contract selected should reduce the asymmetric information between the principal and agent as much as possible. From this, the objective of our econometric analysis is to identify the screening device that enables the bank to discriminate credit granting among firms and select the contract that will incentivize the borrower to fulfill the terms of the contract.

In particular, we want to verify whether the EBRD exploits information about client's previous contract(s) in order to fix the credit size upon signing additional contracts with the same borrower. If it does, as claimed by Lambert (1983), Rogerson (1985), and Chiappori et al. (1994), then it means that the bank uses historical information (i.e., memory) to maximize its profits. To focus on this issue, we proceed by splitting the population into two subpopulations: one of one-contract firms, the other of multi-contract firms. Historical information is available on all firms in the multi-contract subpopulation, and we want to determine whether the EBND has used this information. Though we apply the same independent variables to both subpopulations, we allow for different specifications of fixed-effects estimation techniques.

According to the level of significance of the fixed effects, we can identify (i) the degree of heterogeneity that they account for and (ii) the importance of the reputation effect captured by ad hoc fixed effects in the case of established clients.

\subsection{Econometric Specification}

To perform our econometric exercise, we match data referring to a few characteristics of contracts signed by the EBRD with other data referring to the environment in which the investment project has been carried out. In this way,

\footnotetext{
${ }^{4}$ Equity is considered to be a non-contingent contract.
} 
we account for both the country investment risk and project risk. According to the general theoretical framework discussed in Section 2, the amount of the credit contract should result from a combination of market conditions and the expected return on the investment.

The variables referring to the environment are: the measure of income level in the host market (i.e., GDP per capita), an indicator for political institutions (i.e., degree of democracy [DEM]), time dummies, and a dummy for public clients, who are more likely to be deemed solvent. Concerning the contract, in addition to the value of the credit (IV) granted by the EBRD to the firm, we consider the contract type, the year it was signed, and the value of the investment that the credit refers to (IP). Investment value (IP) approximates the minimum level of return for any successful productive investment by the firm, which corresponds to its capacity for repayment. When adopting this hypothesis, we follow results achieved by Holmström (1999), who showed that the distinguishing characteristics of such investment represent a way to disclose unknown characteristics of an agent when accommodating the dynamic perspective of a reputation effect.

The maturity of a credit differs for each category of contract, and contract type is an indicator that approximates credit maturity, as mentioned in Section 3. We know that the interest rate charged by the EBRD equaled the London Interbank Offered Rate (LIBOR) plus a risk premium, and the value of the LIBOR allows us to capture the current conditions of financial markets. From the bank's point of view, any changes in the LIBOR will affect the credit supply to the firm.

As for the risk premium, data from the EBRD are unavailable, and in our econometric strategy we control for this factor by considering it to be a feature included in the different firm types or contract fixed effects. 5

Box 1. List of variables

\begin{tabular}{|l|l|}
\hline C13 & Type of contract signed by the EBRD (13 possible contracts) \\
\hline LDEM & Logarithm of the index of the democratic level in the country hosting the investment (Polity IV, 2007) \\
\hline PUBLIC & Dummy variable for presence of a public client or other interests of the bank in the project \\
\hline LGDP & Logarithm of gross domestic product per capita of the host country (IMF Statistics, 2007) \\
\hline LIP & Logarithm of the total value of the investment project \\
\hline LIV & Logarithm of the value of the investment financed by the EBRD \\
\hline LLIBOR & Logarithm of the average annual value of the LIBOR interest rate at 12 months \\
\hline FIRST & Dummy for the first contract signed by the EBRD with firms that ultimately obtained multiple credits \\
\hline SECTOR & Dummy by sector \\
\hline YEAR & Time dummy \\
\hline C13FIRST & Interaction term between C13 and FIRST \\
\hline IPFIRST & Interaction term between $I P$ and FIRST \\
\hline
\end{tabular}

To formulate the empirical model, we build our database by considering each contract as a single entry, for which we record all available information that refers to the contract. For this, we define the dependent variable (i.e., value of the granted credit) as $\mathrm{Y}=(\mathrm{IV})$ and $\mathrm{X}=$ (IP, Public, DEM, Libor, GDP) as the vector of the independent variables. Each dependent variable (IV) is defined as IVitjs, in which $i=$ firm, $t=$ year, $j=$ host country, and $s=$ sector. By contrast, our regressors are variables referring to the firm (i.e., IPitjs and Publici) or the host market (i.e., DEMjt and

\footnotetext{
${ }^{5}$ This strategy is suitable for our analysis because we do not center our study on the problem of returns of credit contracts to the EBRD or compare them with those of commercial banks. Any extension in this direction would require complete information about credit contracts.

${ }^{6}$ Referring to Table 1, the contract Loan/Line of credit was excluded because it lacked further identification data.
} 
GDPjt), as well as to the general credit conditions of the financial markets (i.e., LIBORt). We also include an interaction term (Demjt $\times$ yeart) between the democracy index and time dummies to track possible changes of the variable democracy over time in each country with strong implications, for instance, on the protection of property rights.7 As a logarithm, the equation can thus be defined as:

$$
\begin{aligned}
L I V_{i t j s}= & \alpha_{0}+\beta_{1} L I P_{i t j s}+\beta_{2} \text { Public }+\beta_{3} L D E M_{j t}+\beta_{4} L L I B O R+\beta_{5} L G D P_{j t}+ \\
& \beta_{6}\left(L D E M_{j t} \times \text { year }\right)+\varepsilon_{i t j s}
\end{aligned}
$$

Since our database is not a true panel, but a pooling of independent cross-sections over time, we need to control for heterogeneity problems. As Wooldridge (2006) argues, this pooled structure implies that the dependent variable may have different distributions during different periods and that, to control for this, we need to introduce time-fixed effects $(\square \mathrm{t})$. The same reasoning applies to the sector dimension, for which we include some sector-fixed effects ( $\square$ s). As shown in Baltagi (2008), for instance, we also need to include the unobservable time-invariant individualspecific effect $(\square \mathrm{i})$ to control for the heterogeneity problem as much as possible. Controlling for all of these effects allows us to decompose the error term $\square$ itjs as follows:

$$
\varepsilon_{i t j s}=\mu_{i}+\mu_{t}+\mu_{s}+v_{i t i s}
$$

in which $\square \mathrm{i}$ is the unobservable time-invariant individual-specific effect and $\square$ itjs denotes the remaining disturbances, which are now expected to be $I I D\left(0, \sigma_{v}^{2}\right)$.

The choice of the variable $\square \mathrm{i}$ turns out to be crucial for obtaining independence between residuals and the dependent variable. In a standard panel effect, $\square$ i would be simply identified with firm-fixed effects. However, given the structure of our database, the adoption of firm-fixed effects is limited, and we can perform several estimations by alternating different types of fixed effects. We refine the efficiency of the estimation results by adopting various categories of fixed effects. If any difference is revealed, then the estimation results obtained by including different types of fixed effects should disclose complementary insights. It is therefore necessary to locate fixed-effects candidates that do not introduce endogeneity distortions.

The theoretical framework indicates the contract type, once signed, as a possible way to identify fixed effects beyond those in the canon. Contract type is in fact time invariant according to EBRD statements. In our exercises, the fixed effects will be alternatively identified by the following exogenous variables: the contract type granted at time t (i.e., C13) for all clients, and, for established clients, obtaining multiple contracts. For established firms, we also know the contract type signed by the firm at time $t=1$ (i.e., C13FIRST), as well as the value of the investment of the same firm financed at $\mathrm{t}=1$ (i.e., IPFIRST). Therefore, the specification as a logarithm used for estimation can be written as:

$$
\begin{aligned}
L I V_{i t j s}= & \alpha_{0}+\beta_{1} L I P_{i t j s}+\beta_{2} D I_{j}+\beta_{3} L D E M_{j t}+\beta_{4}\left(\text { LLIBOR }_{t}\right)+\beta_{5} L G D P_{j t} \\
& +\beta_{6}\left(\text { LDEM }_{j t} * \text { year }_{t}\right)+\gamma_{1} \text { FE }_{i}+\gamma_{2} \text { Year }_{t}+\gamma_{3} \text { Sector }_{s}+v_{i t j s}
\end{aligned}
$$

Table 2 shows descriptive statistics for some variables in the overall period and two years in specific: 1993 and 2003. The dependent variable is the (logarithm of) financing amount (IVitjs) granted by the EBRD; this is one of the variables in the bank's profit function that depends negatively on the project's riskiness. 8 It reflects both the screening process and the incentive mechanism that occur between clients. The measure of political institutions (DEM) is taken from the Polity IV project, an index ranging between 0 (i.e., absolute autocracy) and 10 (i.e., full-

\footnotetext{
${ }^{7}$ We prefer to rely on this qualitative variable instead of other pure quantitative variables (e.g., $G D P_{j t} \times y e a r_{j t}$ ) because it is more informative of the state-of-right in host countries. Other statistics usually selected to capture the development of a financial system such as those released by the World Bank are unavailable for the sample of countries studied here during the period being considered.

${ }^{8}$ See Stiglitz and Weiss (1981) on credit rationing.
} 
fledged democracy). 9 In our total population, this index declines over time because the EBRD financed democracies in central and eastern Europe at the beginning of the economic transition and later provided finance in autocratic countries of central Asia. The variation of the LIBOR corresponds to the historical values of the credit market during the period.

Relying on the results discussed in Section 2, we expect that the coefficients associated with all independent variables in Equation 2 will be positive. An improvement in the market conditions in host countries is expected to reduce the risk of the investment, meaning that the EBRD will be more likely to finance a greater portion of the investment project. This tendency is also expected to be reinforced by an increase in the LIBOR, thereby making each financing contract more profitable for the bank.

To test the level of individual heterogeneity, we apply the technique of pooled ordinary least squares (OLS) versus fixed effects. 10 Our empirical strategy for identifying a way to isolate the reputation effect in this sample of observations consists of detecting the type of fixed effect that performs best. Referring to current literature, the types of contracts granted by the bank somewhat signal the screening process that the EBRD put in place. From this perspective, we refer to three types of time-invariant fixed effects (C13; C13FIRST; IPFIRST) plus the canonical firm fixed effect considered to be a potential benchmark. By performing a regression with $\mathrm{C} 13$ as fixed effects (i.e., contract fixed effects), we exclude all information about firms' historical track records. When we introduce historical information about individual firms by using C13FIRST or IPFIRST, it is possible to observe whether the past performance of firms affects the conditions of the contract proposed by the bank. If it does, then we can conclude that the bank recalls past information and uses it to adjust the conditions of future contracts with each firm.

Table 2: Descriptive statistics

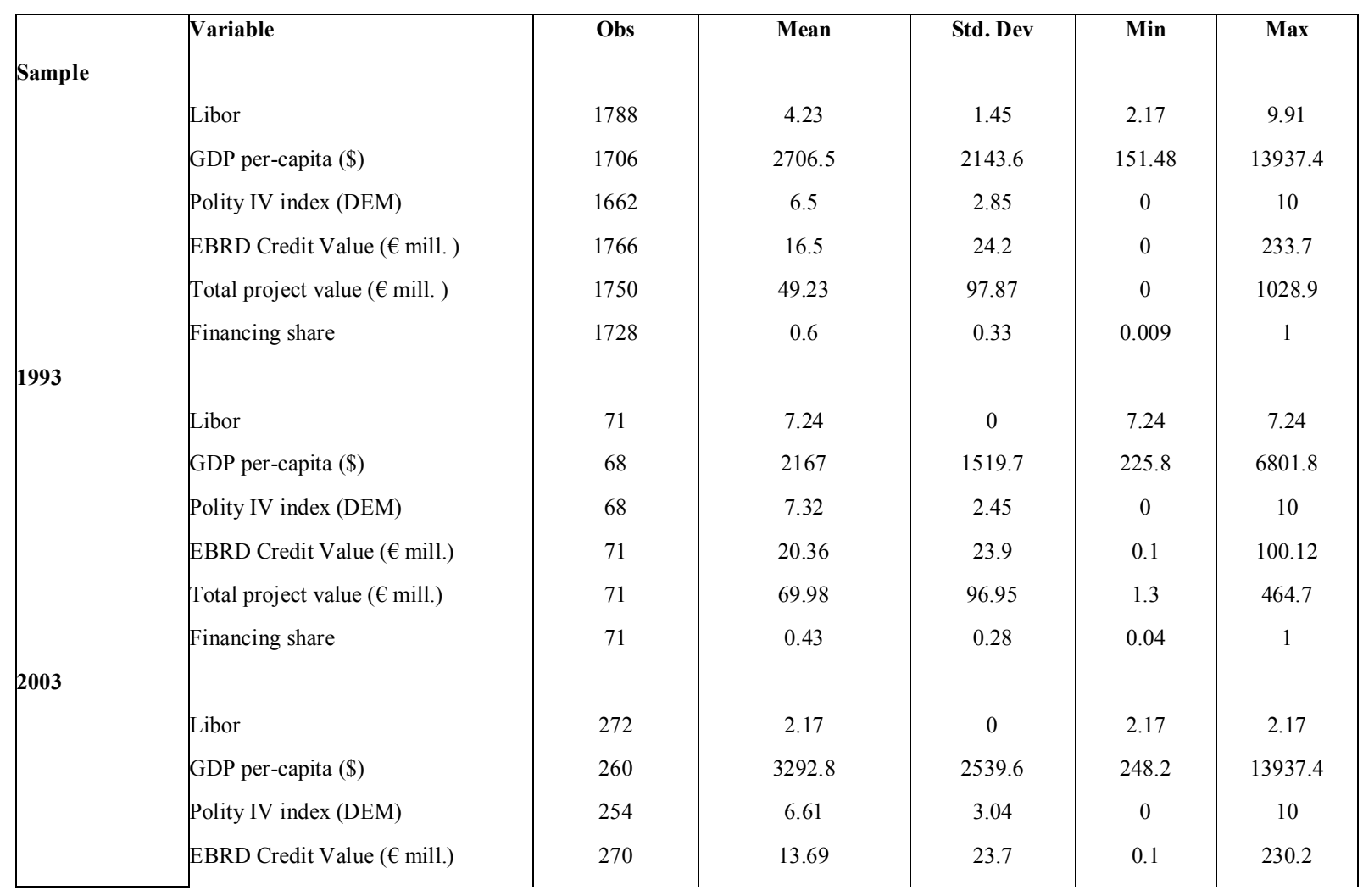

\footnotetext{
${ }^{9}$ According to the Polity IV website (www.systemicpeace.org/polity/polity4.htm), there is no minimum condition for defining a political regime as democratic. Democracy (DEM) is considered to be a variable. The DEM indicator is an additive, 11-point scale derived by the sum of the coding of competitiveness of political participation, the openness and competitiveness of executive recruitment, and constraints on the chief executive.

${ }^{10}$ Econometric estimations were computed with Stata 12.
} 


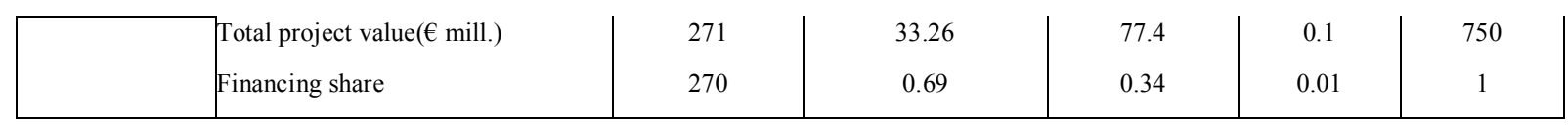

\subsection{Results}

Our database contains all contracts signed by the bank during 1991-2003.11 To test the reputation effect, we run regressions separately for each group of firms - namely, one-contract and multi-contract firms. We proceed first by assessing whether the fixed-effects model should be preferred to the pooled OLS with the F-test and the random effect model with the Hausman test. In all regressions, we control for heteroskedasticity by applying either the White or cluster correction by contract or firm. We lastly test the different measures of time-invariant fixed effects.

\subsubsection{One-contract firms}

The subpopulation of one-contract firms includes 1,168 contracts with 1,168 different firms. Since each contract corresponds to a particular firm but we do not dispose of historical information about the bank-client relationship, we can test only one measure of fixed effects, contract-fixed effects (C13), a qualitative variable that identifies each of the contract types.

The results of the F-test and Hausman test show that the fixed-effects model is preferable to the pooled and randomeffects models (Table 3). By preferring the cluster-error correction version of the estimations, the contract-fixedeffect results reveal interesting insights. The fraction of variance due to fixed effects $(\rho)$ is relatively high $(.70)$.

The estimate of $\rho$ suggests that nearly half of the variation in the amount financed is related to the different contract types (Baltagi, 2008; Baum, 2006). In the fixed-effects estimations, the coefficients of all explanatory variables, provided that they are statistically significant, display the expected sign. The firm's repayment capacity (IPitjs) is always highly significant, and all dummy variables are always statistically significant. The public identity of a client also turns out to be important since a public client may be deemed less risky by the bank than a private one when granting only one credit; this result differentiates this group of contracts from the full population. The significance of the interaction term between democracy (DEMjt) and the time dummy means that the more democratic a country becomes over time, the greater the financing offered by the bank. This result either confirms the official claim that the EBRD promotes democratic institutions in transition economies or indicates that a country shifting toward democracy over time offers more profitable investment opportunities.

In sum, for one-contract firms the contract-fixed effects turn out to be a good measure for identifying individual heterogeneity. Each contract signed by the bank is granted according to the individual characteristics of the client, and the contract itself is a suitable device to control for unknowns when signing a first contract with a firm.

\subsubsection{Multi-contract firms}

The subpopulation of multi-contract firms includes 306 contracts and considers all firms that obtained multiple contracts. We therefore have historical information about each individual firm that we can control for. Given this characteristic, we investigate whether the bank considers a firm's historical track record when signing additional contracts. If it does not, then it means that the bank treats firms of both subpopulations in the same way, thereby ignoring historical information in the subpopulation of multi-contract firms. We thus repeat the previous exercise in its entirety for this subpopulation. To control for heteroskedasticity, we alternatively apply the White and cluster corrections. The cluster correction is important for controlling for the autocorrelation in residuals since each firm appears multiple times in the population (Table 4).

When included, canonical firm-fixed effects (Table 5) perform quite well in term of $\square$ values, and the specification with the cluster-corrected model as the preferred one. In the case of statistical significance, regressors turn out to display the expected coefficient with the exception of PUBLICi, which loses statistical significance as it does in the baseline OLS estimation in Table 4.12 For additional contracts, it might be that the public client does not enjoy a good reputation; it could be identified negatively, for instance, since it is unable to efficiently complete its

\footnotetext{
${ }^{11}$ We therefore consider the population of all granted credits.

${ }^{12}$ The variable $L L I B O R$ was dropped because of a collinearity effect.
} 
investment projects, which reduce its repayment capacity. However, in quantitative terms, the introduction of fixed effects does not strongly improve the goodness-of-fit of the estimations. Furthermore, fixed effects by contract type do not capture individual heterogeneity as well as with firm-fixed effects (Table 5). The value of $\square$ settles around .26 in the case of contract fixed effects, which is far lower than that shown in Table 3, while that of firm-fixed effects that we consider to be a benchmark since it embeds individual heterogeneity firm by firm reaches .75 . This finding emphasizes the existence of important features shared by firms that affect the content of credit contracts addressed to different clients. As a result, we conclude that the model with contract-type (C13) fixed effects does not perform quite as well for this subpopulation, though these estimations are preferable to the pooled and randomeffects estimations.

We therefore need to examine other measures of fixed effects in order to control for the reputation effect of clients to whom the EBRD granted multiple credits. In our database, we are able to identify the potential reputation of a client by isolating the first type of contract and the value of the first investment (i.e., repayment capacity) for a firm that appears multiple times in our database. We then match these values to subsequent contracts signed by the same firm. To avoid endogeneity problems, we extract from this subsample of multi-contract firms entries that correspond to the first contract for all firms and firms with multiple contracts signed in the same year (as the first entry) since we are unable to determine their chronological order.

Table 3. Econometric results: One-contract firms

Method of estimation: OLS and Fixed effects, Clustering by contract (C13), Value in brackets: Std Error,

Dependent variable: LIV

\begin{tabular}{|c|c|c|c|c|}
\hline & OLS & OLS & Fixed effects & Fixed effects \\
\hline C & $-1.73(0.63)^{* * *}$ & $-1.72(0.20)^{* * *}$ & $-2.24(0.8)^{* * *}$ & $-2.24(0.3)^{* * *}$ \\
\hline LIP & $0.81(0.01)^{* * *}$ & $0.81(0.02)^{* * *}$ & $0.77(0.01)^{* * *}$ & $0.77(0.01)^{* * *}$ \\
\hline PUbliC & $0.30(0.07)^{* * *}$ & $0.30(0.09)^{* * *}$ & $0.23(0.07)^{* * *}$ & $0.23(0.05)^{* * *}$ \\
\hline LDEM & $0.16(0.24)$ & $0.16(0.06)^{* *}$ & $0.18(0.34)$ & $0.18(0.03)^{* * *}$ \\
\hline LLIBOR & $1.05(0.70)$ & $1.05(0.15)^{* * *}$ & $1.25(0.81)$ & $1.25(0.19)^{* * *}$ \\
\hline LGDP & $0.01(0.03)$ & $0.01(0.02)$ & $0.04(0.03)$ & $0.04(0.02)$ \\
\hline Dummy years & yes & yes & yes & yes \\
\hline Dummy sectors & yes & yes & yes & yes \\
\hline DEM*years & yes & yes & yes & yes \\
\hline Fixed effects & & & $\mathrm{C} 13$ & $\mathrm{C} 13$ \\
\hline Tests: & & & & \\
\hline Hausman Test ( IIL ) & & & $228.9^{* * *}$ & \\
\hline F-test: fixed vs pooled & & & $9.69 * * *$ & \\
\hline D. Years $=0$ & 1.55 & $751^{* * *}$ & 0.99 & $2189.87^{* * *}$ \\
\hline D. Sectors $=0$ & $3.65^{* * *}$ & $12071^{* * *}$ & $3.21 * * *$ & $6743^{* * *}$ \\
\hline DEM $*$ year $=0$ & $2.05 * *$ & 52203 PNP & $1.92 * *$ & $3177.95 * * *$ \\
\hline DEM*year=D. Y ears & $2.26^{* * *}$ & $1.4 \mathrm{e}+10 * * *$ & $1.97 * *$ & $369.73^{* * *}$ \\
\hline$\sigma_{u}$ & & & 0.51 & 0.51 \\
\hline$\rho$ & & & 0.43 & 0.43 \\
\hline Robustness errors & White & Cluster & White & Cluster \\
\hline R-Square (within) & 0.84 & 0.84 & 0.82 & 0.82 \\
\hline OBS & 1168 & 1164 & 1164 & 1164 \\
\hline
\end{tabular}


*** $1 \%$ significance level; ** 5\%; * 10\%

Table 4. Econometric results: Several-contract firms

Method of estimation: OLS, Clustering by contracts (C13), Value in brackets: Std Error,

Dependent varibale: LIV

\begin{tabular}{|c|c|c|}
\hline & OLS & OLS \\
\hline C & $0.77(1.69)$ & $-4.90(057)^{* * *}$ \\
\hline LIP & $0.87(0.33)^{* * *}$ & $0.87(0.04)^{* * *}$ \\
\hline PUBLIC & $0.02(0.20)$ & $0.02(0.27)$ \\
\hline LDEM & $0.94(0.45)^{* *}$ & $0.95(0.21)^{* * *}$ \\
\hline LLIBOR & Dropped & Dropped \\
\hline LGDP & $0.01(0.07)$ & $0.002(0.07)$ \\
\hline Dummy years & Yes & yes \\
\hline Dummy sectors & Yes & yes \\
\hline DEM*years & Yes & yes \\
\hline D. Years $=0$ & $4.82 * * *$ & $4.3 \mathrm{e}+08 * * *$ \\
\hline D. Sectors $=0$ & $5.19^{* * *}$ & $403.6^{* * *}$ \\
\hline DEM $*$ year $=0$ & $4.90^{* * *}$ & $4.6 \mathrm{e}+09 * * *$ \\
\hline DEM $*$ year $=D$. Y ears & $4.73^{* * *}$ & $2.3 \mathrm{e}+09 * * *$ \\
\hline Robustness errors & White & Cluster \\
\hline Adj. R-Square & 0.82 & 0.82 \\
\hline OBS & 306 & 304 \\
\hline
\end{tabular}

$* * * 1 \%$ significance level; $* * 5 \% ; * 10 \%$ 
Table 5. Econometric results: Several-contract firms Method of estimation: Fixed effects, Value in brackets: Std Error,

Dependent variable: LIV

\begin{tabular}{|c|c|c|c|c|}
\hline & Fixed effects & Fixed effects & Fixed effects & Fixed effects \\
\hline C & $-5.27(5.33)$ & $-5.27(0.50)^{* * *}$ & $-6.63(3.00)^{* *}$ & $-6.63(3.28)^{* *}$ \\
\hline LIP & $0.84(0.033)^{* * *}$ & $0.84(0.05)^{* * *}$ & $0.76(0.05)^{* * *}$ & $0.76(0.04)^{* * *}$ \\
\hline PUblic & $-0.73(0.23)$ & $-0.07(0.28)$ & $-0.21(0.35)$ & $-0.21(0.31)$ \\
\hline LDEM & $0.99(0.43)^{* *}$ & $0.99(0.15)^{* * *}$ & $6.54(2.14)^{* * *}$ & $6.54(2.32)^{* * *}$ \\
\hline LLIBOR & Dropped & Dropped & Dropped & Dropped \\
\hline LGDP & $0.07(0.07)$ & $0.07(0.07)$ & $0.14(0.22)$ & $0.14(0.18)$ \\
\hline Dummy years & yes & yes & yes & yes \\
\hline Dummy sectors & yes & yes & yes & yes \\
\hline DEM*years & yes & yes & yes & yes \\
\hline $\begin{array}{l}\text { Fixed effects } \\
\text { Tests: }\end{array}$ & $\mathrm{C} 13$ & $\mathrm{C} 13$ & Firm & Firm \\
\hline F-test: fixed vs pooled & $5.69^{* * *}$ & & $1.73^{* * *}$ & \\
\hline D. Years $=0$ & $3.09^{* * *}$ & $403.78^{* * *}$ & $2.00 * *$ & $25.27 * * *$ \\
\hline D. Sectors $=0$ & $2.40^{* * *}$ & $35.38 * * *$ & 0.25 & $7.75^{* * *}$ \\
\hline DEM $*$ year $=0$ & $2.99^{* * *}$ & $28.71 * * *$ & $1.95 * *$ & $22.63 * * *$ \\
\hline DEM*year=D. Years & $3.08^{* * *}$ & $1080^{* * *}$ & $1.90^{* *}$ & $39.28 * * *$ \\
\hline $\boldsymbol{\sigma}_{u}$ & 0.39 & 0.39 & 1.03 & 1.03 \\
\hline$\gamma$ & 0.26 & 0.26 & 0.75 & 0.75 \\
\hline Robustness errors & White & $\begin{array}{c}\text { Cluster } \\
\text { (by contract) }\end{array}$ & White & $\begin{array}{c}\text { Cluster } \\
\text { (by firm) }\end{array}$ \\
\hline R-Square (within) & 0.83 & 0.83 & 0.70 & 0.70 \\
\hline OBS & 304 & 304 & 306 & 306 \\
\hline
\end{tabular}

$* * * 1 \%$ significance level; $* * 5 \% ; * 10 \%$ 
In this way, we use historical information included in the subpopulation by testing two measures of reputation, namely by exploiting two indicators of contract fixed effects defined as C13FIRST and IPFIRST.

Each of these measures contains the historical information because it considers information associated with the first contract signed by each firm (FIRST). The variable IPFIRST represents the project value of the first contract, while the variable C13FIRST is the type of the first contract signed. The present exercise yields an important result: the fixed effects associated with the project value of the first contract are a good measure to account for individual heterogeneity in the subpopulation.

In Table 6, we present results obtained by introducing the standard contract fixed effects (C13), whereas in Table 7 we consider the two novel measures of reputation, IPFIRST- and C13FIRST-fixed effects. Estimation results shown in Table 6 remain nearly unchanged when compared to those of the contract-fixed effects shown in Table 5. The chief novelty in these last estimations is the negative coefficient, even if only of weak statistical significance, associated with the identity of the client, particularly public ones. This result reinforces the argument presented above: in the case of repeated contracts, it seems that a public client is not a type of client targeted by the EBRD. Perhaps such clients have access to other sources of financing or cannot be relied upon to fulfil contractual commitments. Moreover, in the sample composed solely of additional contracts (Table 6), contract C13) fixed-effect estimations are not any more informative of the reputation effect of the clients than they are for one-contract firms. In Table 7, the adoption of fixed effects as the first contract type granted to a firm (C13FIRST) does not deliver any important improvement in the goodness-of-fit of the model, and the statistical significance of the regressors remains more or less unchanged when contract-fixed effects are adopted.13

By contrast, whenever the project value of the first contract (IPFIRST) is included as a fixed effect, the value of $\square$ increases strongly (Table 7), as does the statistical significance of the regressors included in the estimation. This last fixed effect is a measure of the reputation of established clients and evidence of the presence of memory. The project value of the first contract is historical information for the bank that provides evidence about the ability of the managers to complete investment projects; knowing ex post the rate of return of that operation, the bank can approximate the effective credit-repayment capacity of the firm (i.e., reputation effect) for the credit that the firm currently seeks. However, the first type of contract (C13FIRST) is not as informative of the historical track record of clients. In the estimation including IPFIRST, the project value (IPitjs) is always statistically significant, and the coefficient has the expected sign. Meanwhile, other variables gain part of their statistical significance when compared with the previous exercise and keep their expected signs. Again, being a public partner no longer has strategic importance, and the absence of historical information about clients obliges the bank to rely on other available variables (e.g., public ownership) to control for unknown information. Once the bank begins to work with established clients, the previous public-status effect is replaced by a more specific client-reputation effect.

To conclude, the reputation effect (i.e., the memory of the first contract) seems to override the problem of unknown information in the bank-client relationship. In the case of firms that gained multiple credits from the EBRD, memory allowed the bank to discriminate credit size according to individual historical characteristics and offer tailored contracts.

\section{Conclusions}

At the beginning of the transition period, the EBRD's lending policy was tied to a combination of its specific objectives in former socialist countries and the constraints associated with the lack of information about its clients. The need to cope with high-credit risk unambiguously forced the EBRD to adopt protective measures by way of a client-screening scheme.

The dataset we built from the records of the EBRD has allowed us to focus empirically on how the reputation effect impacted the size of credits granted to established clients. At the same time, the properties of the fixed-effects estimation technique have allowed us to deal with issue.

As discussed in the literature, no unique scheme has been available for implementation. Our strategy of analysis facilitates splitting our population into two groups: one of clients who received one contract and another of clients who received multiple contracts.

\footnotetext{
${ }^{13}$ It is notable that the $\rho$ of the regression with C13FIRST-fixed effects is also lower than that of $C 13$-fixed-effects estimations.
} 
Table 6. Econometric results: Second and further contracts Method of estimation: OLS and Fixed effects, Value in brackets: Std Error,

Dependent variable: LIV

\begin{tabular}{|c|c|c|c|c|}
\hline & OLS & OLS & Fixed effects & Fixed effects \\
\hline C & $-4.66(4.21)$ & $-2.38(2.37)$ & $-0.98(3.55)$ & $98.91(26.82)^{* * *}$ \\
\hline LIP & $0.84(0.04)^{* * *}$ & $0.86(0.07)^{* * *}$ & $0.85(0.04)^{* * *}$ & $0.84(0.08)^{* * *}$ \\
\hline PUBLIC & $-0.50(0.27)^{*}$ & $-0.51(0.46)$ & $-0.68(0.37)^{*}$ & $-0.68(0.4)^{* * *}$ \\
\hline LDEM & $1.33(0.66)^{* *}$ & $1.31(0.17)^{* * *}$ & $1.05(0.53)^{*}$ & $1.05(0.36)^{* *}$ \\
\hline LLIBOR & Dropped & Dropped & Dropped & Dropped \\
\hline LGDP & $0.09(0.10)$ & $0.08(0.09)$ & $0.11(0.09)$ & $0.11(0.09)$ \\
\hline Dummy years & yes & Yes & yes & yes \\
\hline Dummy sectors & yes & Yes & yes & yes \\
\hline DEM*years & yes & Yes & yes & yes \\
\hline Fixed effects & & & $\mathrm{C} 13$ & $\mathrm{C} 13$ \\
\hline Tests: & & & & \\
\hline F-test: fixed vs pooled & & & $6.71^{* * *}$ & \\
\hline D. Years $=0$ & $8.60^{* * *}$ & $316.71^{* * *}$ & $4.40^{* * *}$ & $2744.15^{* * *}$ \\
\hline D. Sectors $=0$ & $1.65^{*}$ & $77.43 * * *$ & 1.41 & $41.32 * * *$ \\
\hline DEM $*$ year $=0$ & $7.98^{* * *}$ & $37.60 * * *$ & $3.94 * *$ & $376.26^{* * *}$ \\
\hline DEM*year=D. Y ears & $7.54 * * *$ & $156.53^{* * *}$ & $4.06^{* *}$ & $463.20^{* * *}$ \\
\hline $\boldsymbol{\sigma}_{u}$ & & & 0.61 & 0.61 \\
\hline$\rho$ & & & 0.49 & 0.49 \\
\hline Robustness errors & White & $\begin{array}{c}\text { Clusters } \\
\text { (by sectors) }\end{array}$ & White & $\begin{array}{c}\text { Clusters } \\
\text { (by sectors) }\end{array}$ \\
\hline R-Square (within) & 0.85 & 0.85 & 0.88 & 0.80 \\
\hline OBS & 169 & 168 & 168 & 168 \\
\hline
\end{tabular}

$* * * 1 \%$ significance level; $* * 5 \% ; * 10 \%$ 
Table 7. Econometric results: Second and further contracts

Method of estimation: Fixed effects, Value in brackets: Std Error,

Dependent variable: LIV

\begin{tabular}{|c|c|c|c|c|}
\hline & Fixed effects & Fixed effects & Fixed effects & Fixed effects \\
\hline C & $-4.70(4.21)$ & $-4.70(6.28)$ & $-11.96(11.56)$ & $-53.27(15.63)^{* * *}$ \\
\hline LIP & $0.80(0.05)^{* * *}$ & $0.80(0.06)^{* * *}$ & $0.70(0.07)^{* * *}$ & $0.70(0.07)^{* * *}$ \\
\hline PUBLIC & $-0.58(0.38)$ & $-0.58(0.30)$ & $-0.72(0.66)$ & $-0.72(0.67)$ \\
\hline LDEM & $1.27(0.57)^{* *}$ & $1.27(0.66)$ & $14.98(8.63)^{*}$ & $14.98(4.88)^{* * *}$ \\
\hline LLIBOR & Dropped & Dropped & Dropped & Dropped \\
\hline LGDP & $0.07(0.10)$ & $0.07(0.07)$ & $1.08(0.50)^{* *}$ & $1.08(0.49)^{* *}$ \\
\hline Dummy years & Yes & Yes & yes & yes \\
\hline Dummy sectors & Yes & Yes & yes & yes \\
\hline DEM*years & Yes & Yes & yes & yes \\
\hline Fixed effects & C13FIRST & C13FIRST & IPFIRST & IPFIRST \\
\hline Tests: & & & & \\
\hline F-test: fixed vs pooled & $1.83^{*}$ & & $1.75^{* *}$ & \\
\hline D. Years $=0$ & $4.29 * * *$ & $1179.15 * *$ & 1.68 & $6.71 * * *$ \\
\hline D. Sectors $=0$ & 1.12 & $13.48 * * *$ & 1.37 & $2.93 * *$ \\
\hline DEM ${ }^{*}$ year $=0$ & $3.89 * * *$ & $7867.7 * * *$ & 1.70 & $198.96^{* * *}$ \\
\hline DEM $*$ year $=D$. Y ears & $3.80 * * *$ & $2100.92 * *$ & 1.68 & $180.17 * * *$ \\
\hline $\boldsymbol{\sigma}_{u}$ & 0.50 & 0.50 & 7.54 & 7.58 \\
\hline$\rho$ & 0.36 & 0.36 & 0.99 & 0.99 \\
\hline Robustness errors & White & $\begin{array}{c}\text { Cluster } \\
\text { (by C13FIRST) }\end{array}$ & White & $\begin{array}{c}\text { Cluster } \\
\text { (by IPFIRST) }\end{array}$ \\
\hline R-Square (within) & 0.85 & 0.85 & 0.85 & 0.85 \\
\hline OBS & 166 & 166 & 157 & 157 \\
\hline
\end{tabular}

$* * * 1 \%$ significance level; ** 5\%; * 10\%

As a novelty, we were able to identify that the effectiveness of the screening device differs concerning the two subgroups. A screening device as general as the type of contract turned out to be an efficient tool, yet only when considering the one-contract subpopulation. In estimations referring to clients with only one credit contract, the importance of cluster correction in the absence of memory effects suggests that the EBRD probably designed various types of contracts, each one tailored to the market conditions of a specific sector. It then offered these 
contracts to clients who wanted to invest in a particular sector in a particular country. This result can be interpreted as a practical way to cope with the credit risk of non-established clients.

As another novelty, we were able to identify that the approximation of the potential returns of the first investment project financed by the EBRD served as the most effective screening device to determine the size of the credit in financing additional projects to so-called established clients.

We have thus been able to perform an econometric analysis confirming a few relevant predictions discussed in contract theory. Unfortunately, the data at hand lacked sufficient information for evaluating the precise returns of financed investments and for measuring their economic impact in host countries. Having this missing material would yield additional interesting conclusions. First, we would be able to refine the structure of the exercise proposed by improving the measurement of a few variables. Second, controlling for the rate of success of the financed projects might offer more insights into the possible association between the optimality of the creditscreening process and the effective impact of financed investments on host-market economies.

Further contributions in this direction would be welcomed above all from a policy-oriented perspective. The EBRD's experience was unique, both because of its mission and the economic environment in which it operated. Nevertheless, in this analysis we have proposed a few ideas to implement an empirical strategy that provides novel insights and opens potential paths for application in other cases. For this, we propose analyzing credit issues in developing countries, where the market risk is an extremely important factor in determining credit-granting strategies, as well as in more sophisticated economic settings, where negotiating risks for commercial firms amid a competitive environment is subject to, for example, financial shocks.

\section{Acknowledgments}

We are grateful to R. Caminal, I. Fernandez -Val, A. Rimbaldi, I. Macho-Stadler, and M. Raiser, as well as participants at the seminar at SUNY, the 62nd ESEM conference, the 35th EARIE conference, and the XXXIII Simposio de Análisis Económico for their useful suggestions and discussions. Any remaining errors are our responsibility. Support from 2013SGR327 and XRAPP is also gratefully acknowledged.

\section{References}

Artige, L., Nicolini, R. (2013) "Institutions and market creation: evidence from the experience of transition countries", SSRN Discussion paper \#2334130,:http://papers.ssrn.com/sol3/papers.cfm?abstract_id=2334130

Baltagi, B. (2008): Econometric Analysis of Panel Data, Wiley \& Son, 4th edition, Chichester.

Baum, Ch. (2006):An introduction to Modern Econometrics using Stata, STATA Press, College Station.

Besley, T, Dewatripont, M and Guriev, S. (2010): "Transition and transition impact", Report for the EBRD's Office of the Chief Economist.

Chiappori, P. A., Macho Stadler, I., Rey, P., Salanié, B. (1994): "Repeated Moral Hazard: The Role of Memory, Commitment, and the Access to the Credit Markets", European Economic Review, vol.38, pp.1527-1553.

EBRD (1999): "Financing EBRD", EBRD Press, London.

Holmström, B. (1999): "Incentive problems: A Dynamics Perspective", The Review of Economics Studies, vol.66 (1), pp. $169-182$.

Inderst, R., Mueller, H.M. (2006):"Informed Lending and Security Design",Journal of Finance, vol. LXI (5), pp. 2137-2162.

Lambert, R.A.(1983): Long-Term Contracts and Moral Hazard,The Bell Journal of Economics, vol.14 (2), pp.441452.

Lanine, G., Vander Vennet, R. (2007): "Microeconomic determinants of acquisitions of Eastern European banks by Wester European banks", Economics of Transition, vol. 15(2), pp. 285-308. 
Manove, M., Padilla, A.J.,Pagano, M. (2001): "Collateral versus Project Screening: A Model of Lazy Banks', The RAND Journal of Economics, vol. 32(4), pp. 726-744.

Polity IV project (2007), www.cidem.umd.edu/polity/.

Rogerson, W. (1985):"Repeated Moral Hazard",Econometrica, vol.53, pp. 69-76.

Dinç, I. S. (2005): "Politicians and banks: Political influences on government-owned banks in emerging markets", Journal of Financial Economics, vol. 77, pp. 453-479.

Stiglitz, J., Weiss, A.(1981):"Credit Rationing in Markets with Imperfect Information",American Economic Review, vol. 71(3), pp. 393-410.

Stiglitz, J., Weiss, A.(1983):"Incentives Effects of Terminations: Applications to the Credit and Labor Markets",American Economic Review, vo. 73, pp. 912-927.

Vuylsteke, Ch. (1995): "The EBRD: its mandate, instruments, challenges and responses", MOCT-MOST: Economic Policy in Transitional Economics, vol. 5(2), pp. 129-155.

Wooldridge, J. (2006):"Introductory Econometrics. A Modern Approach", 3rd edition, Thomson South-Western.

\section{Appendix A: List of sectors}

The following table shows all the sectors included in our sample:

\begin{tabular}{|l|l|}
\hline Banking, Finance and holding & Local services (water, waste...) \\
Chemical (including Pharmaceutical) & Media \\
Education and other public services & Manufacturing \\
Electronic and Hi-Tech & Metal \\
Energy & Natural resources \\
Environment & Oil and gas \\
Food and beverage (incl. agriculture) & Real estate \\
Health and personal care & Telecommunication \\
Hotels and tourism & Trade and retail \\
Infrastructure (transport) & Vehicles \\
\hline
\end{tabular}

